Published in final edited form as:

Pediatr Clin North Am. 2017 June ; 64(3): 641-658. doi:10.1016/j.pcl.2017.01.007.

\title{
Hepatitis B and C
}

Wikrom Karnsakul, MD and

Associate Professor, Pediatric Liver Center, Department of Pediatrics, Johns Hopkins University School of Medicine, Baltimore, Maryland, USA

Kathleen B Schwarz, MD

Professor, Pediatric Liver Center, Department of Pediatrics, Johns Hopkins University School of Medicine, Baltimore, Maryland, USA

\section{Synopsis}

Provide a brief summary of your article (100 to 150 words; no references or figures/tables). The synopsis appears only in the table of contents and is often used by indexing services such as PubMed Chronic viral hepatitis continues to be a global health threat and a financial burden. Hepatitis B and C viruses (HBV and HCV) are the most common causes of chronic viral hepatitis in the United States. The majority of cases are asymptomatic during childhood and young adulthood. Cirrhosis and hepatocellular carcinoma are rare during childhood but commonly expected in adulthood. Efforts from worldwide health organizations, pharmaceutical industries, and clinical and research institutions have resulted in much new knowledge, very effective therapy for HCV-infected children and the promise of new effective therapies for HBV-infected children. For HCV-infected children the current standard of care is pegylated interferon and ribavirin but clinical trials with highly effective direct acting antiviral agents are currently underway in the pediatric age group. There are currently 5 FDA-approved agents for HBV-infected children: alphainterferon, lamivudine, adefovir, tenofovir, and entecavir. However treatment with these agents seldom results in a functional cure and more effective therapies are urgently needed

\section{Keywords}

Hepatitis B; hepatitis C; sustained virologic response; pegylated interferon; direct acting antiviral agents; spontaneous viral clearance

\footnotetext{
Correspondence to: Wikrom Karnsakul.

author Contact information

WK-600 N. Wolfe Street - CMSC 2-117, Baltimore, MD 21287 Phone (410) 955-8769, Fax (410) 9551464

KBS-600 N. Wolfe Street - CMSC 2-116, Baltimore, MD 21287 Phone (410) 614-4722, Fax (410) 9551464

disclosure statement

WK-I have had a relationship with Gilead as a sponsor for an open-Label, Multicenter, Multi-cohort, Single-Arm Study to Investigate the Safety and Efficacy of Sofosbuvir + Ribavirin in Adolescents and Children with Genotype 2 or 3 Chronic HCV Infection and a Phase 2, Open-Label, Multicenter, Multi-cohort Study to Investigate the Safety and Efficacy of Ledipasvir/Sofosbuvir Fixed Dose Combination in Adolescents and Children with Chronic HCV-Infection and a Long Term Follow-up Registry for Adolescent and Pediatric Subjects Who Received a Gilead Hepatitis C Virus Direct Acting Antiviral (DAA) in Chronic Hepatitis C Infection Trials . KBS - Research grants from NIDDK, Gilead, BMS, and Roche; consulting for Gilead, Roche/Genentech, and Up to Date

Publisher's Disclaimer: This is a PDF file of an unedited manuscript that has been accepted for publication. As a service to our customers we are providing this early version of the manuscript. The manuscript will undergo copyediting, typesetting, and review of the resulting proof before it is published in its final citable form. Please note that during the production process errors may be discovered which could affect the content, and all legal disclaimers that apply to the journal pertain.
} 
Viral hepatitis has been a global health concern and economic burden for over the past century. Hepatitis B and C viruses (HBV and HCV) are the most common causes of chronic viral hepatitis in the United States as well as worldwide. However, the presentation depends on the type of virus and the age of the patients. Children with HBV rarely have acute severe hepatitis. Most children with HBV and HCV are asymptomatic during childhood but are at risk for developing cirrhosis and hepatocellular carcinoma (HCC) in the adulthood. In this chapter HIV co-infection is not discussed.

\section{HBV}

\section{Epidemiology and Natural History}

The number of cases of chronic HBV infection has been estimated at almost 400 million worldwide ( $\sim 5 \%$ of world's population). HBV has 8 genotypes (A-H) which are associated with moderate differences in response to therapy. (1) Children with chronic hepatitis B (CHB) (genotype B and C) have a high frequency of HBeAg positivity and high HBV DNA levels compared to those with other genotypes and the timing of $\mathrm{HBeAg}$ seroconversion in genotype $\mathrm{C}$ is more delayed compared to genotype $\mathrm{B}$. Genotype $\mathrm{C}$ results in more aggressive hepatitis and is associated with an increased risk of HCC. (2) However the development of HCC was associated with genotype B in a single Taiwanese pediatric study. (2) The prevalence of chronic HBV infection in pregnant women in urban areas of the USA varies by race and ethnicity. (3)While the highest rate was observed in Asian women (6\%), the rates in black, white and Hispanic women were $1,0.6$ and $0.14 \%$, respectively.

Maternal-fetal transmission is currently the most common route of HBV transmission because meticulous screening for HBV has been performed in individuals receiving transfusion of blood products. Perinatal transmission occurs at or close to the time of birth as a result of exposure to maternal blood and cervical secretions. Transplacental transmission presumably is responsible for perinatal infections depending on risk factors including maternal HBeAg positivity, HBsAg titer and HBV DNA level. (4) Infants born to mothers positive for $\mathrm{HBeAg}$ and mothers with very high serum DNA levels $\left(\left(>=10^{9}\right.\right.$ copies per $\left.\mathrm{mL}\right)$ are at risk for acquiring HBV despite receiving active and passive immunization within 24 hours postpartum.(5-7) Transplacental transmission can occur due to leakage, such as during a threatened abortion. Amniocentesis in HBsAg positive mothers can be another risk of HBV transmission. (8) Although HBsAg and HBV DNA can be detected in the colostrum and breast milk of $\mathrm{HBV}$-infected mothers, several studies have shown that there is no additional risk of transmission of HBV to breast-fed infants of infected mothers, provided that completed active and passive immunoprophylaxis is received. $(9,10)$ Wang et al compared outcomes among three groups of infants of HBsAg+ mothers: 144 born by spontaneous vaginal delivery, 40 by forceps or vacuum extraction and 117 by cesarean section all of whom received the HBV vaccine and the hepatitis B immunoglobulin (HBIG). (11) As the response rates to recommended passive and active immunoprophylaxis were similar in all groups in the infants, at one year of age, anti-HBs was detected in $78.9 \%$ of the infants born by normal vaginal delivery, $84.6 \%$ by forceps or vacuum extraction, and $86.4 \%$ by cesarean section with $\mathrm{CHB}$ incidence of 7.3, 7.7 and $6.8 \%$, respectively. The mode of delivery does not likely influence HBV transmission. A higher incidence of low birth weight 
and prematurity has been reported in infants born to mothers infected with HBV compared to those born to uninfected mothers. (12)

The spontaneous seroconversion rates of HBeAg (loss of HBeAg and development of anti$\mathrm{HBe}$ ) for children infected via perinatal transmission are less than $2 \%$ per year for those under age 3 years, and $4-5 \%$ per year in those older than 3 years, whereas children infected after the perinatal period have higher rates of spontaneous $\mathrm{HBeAg}$ seroconversion, up to 70 $-80 \%$ over 20 years. The time to $\mathrm{HBeAg}$ clearance for individuals with $\mathrm{HBV}$ genotype $\mathrm{C}$ is longer than in patients with other genotypes (13). Since the early 1990s, the incidence of acute HBV in the United States has declined (14).

About $1 / 3$ of older children and adolescents with acute HBV infection will develop classical symptoms of hepatitis. Cirrhosis and hepatocellular carcinoma mostly in adulthood may be anticipated in about $25 \%$ of those who acquire HBV infection during infancy or childhood. Approximately $90 \%$ of children infected as infants will develop chronic HBV infection (CHB). The risk falls to $25-50 \%$ for children who become infected after early infancy but before age 5 years, and to only $5-10 \%$ for children who become infected in adolescents or adulthood. Most children with CHB are asymptomatic, grow and develop normally. Like adults, children and adolescents who are immune active with persistent elevation of alanine aminotransferase and histologic findings of liver inflammation and fibrosis have an increased risk of cirrhosis and HCC compared to those without evidence of hepatic inflammation. $(15,16)$

\section{Diagnosis and Tests}

The diagnosis of acute hepatitis B is based upon the detection of HBsAg (hepatitis B surface antigen) as an initial serological marker and $\operatorname{IgM}$ anti-HBc (IgM antibody to hepatitis B core antigen). Early in the course of acute infection, HBeAg and HBV DNA are detected and are markers of active viral replication. As patients recover, serum HBV DNA significantly declines but may remain detectable by polymerase chain reaction (PCR) assay for up to several decades. Anti-HBc IgM is the initial antibody, which usually persists for several months. During the window period anti-HBc IgM may be present as the only marker of acute HBV infection (after HBsAg is cleared and before anti-HBs is detected). The development of anti-HBc IgG and anti-HBs indicates recovery from acute HBV infection. Seroconversion ( $\mathrm{HBeAg}$ to anti-HBe) occurs and is followed by a decrease in serum HBV DNA levels; and eventually, HBsAg becomes undetectable. Persistence of HBsAg for longer than 6 months indicates an HBV carrier or progression to CHB. During the early phase of $\mathrm{CHB}, \mathrm{HBeAg}$ and high serum HBV DNA levels are markers of HBV replication.

Different serologic patterns are observed at various phases of CHB (Table 1) : immune tolerant phase, immune active phase, inactive (HBeAg negative), inactive (loss of $\mathrm{HBsAg}$ ), and $\mathrm{HBeAg}$ negative immune reactivation phase. The immune tolerant phase is characterized by normal or mildly elevated serum aminotransferases (ALT $<1.5$ times the upper limit of normal) and evidence of active HBV replication (HBV DNA $>20,000 \mathrm{IU} / \mathrm{mL}$ or $10^{5}$ copies/mL). HBsAg and HBeAg are positive. Children with maternal-fetal transmission may remain in this phase up to several decades and are less likely to respond to antiviral therapies compared to immune active children. Immune active hepatitis is 
characterized by elevated serum aminotransferases (ALT $>1.5$ to 2 times the upper limit of normal) and active HBV replication (HBV DNA is typically $>20,000 \mathrm{IU} / \mathrm{mL}$ or $10^{5}$ copies/ $\mathrm{mL}$ ). HBsAg and $\mathrm{HBeAg}$ are positive. During this phase children are more likely to clear $\mathrm{HBeAg}$ spontaneously or to respond to antiviral therapies. Inactive $\mathrm{CHB}$ phase ( $\mathrm{HBeAg}$ negative), also known as the non-replicative or latent phase, is characterized by normal levels of serum aminotransferases and low or undetectable levels of HBV replication. HBsAg is positive but $\mathrm{HBeAg}$ is negative. Up to 20 percent of children with the nonreplicative phase undergo reversions to the immune active phase, and 20 to 30 percent reactivate into $\mathrm{HBeAg}$-negative $\mathrm{HBV}$. (17) Inactive $\mathrm{CHB}$ (loss of $\mathrm{HBsAg}$ ) occurs in a minority of children who clear $\mathrm{HBeAg}$ as well as the $\mathrm{HBV}$ infection (clearance of $\mathrm{HBsAg}$ and appearance of anti-HBs). However the state of negative serologic markers of active infection, including loss of HBsAg, is now referred to as a "functional cure" because such individuals probably have residual ccc HBV DNA and therefore remain at risk for reactivation which receiving immunosuppressants such as chemotherapy for cancer. During the HBeAg negative immune reactivation phase, children have increased HBV DNA levels with normal or elevated serum aminotransferases and have more virulent liver disease. (18)

Screening tests for HBV are recommended for children and adolescents with clinical signs of hepatitis or unexplained elevation of serum aminotransferases, for all internationally adopted children, all pregnant adolescents, adolescents who engage in high-risk behaviors including the use of intravenous or intranasal drugs or unprotected sex with an infected partner or more than one partner, for men who have sex with men, and those with a history of sexually transmitted disease, immigrants from high prevalence areas (HBsAg prevalence is $>2 \%$ ) including Africa and Asia, the Cape Verde islands, most of Eastern and Mediterranean Europe, the Caribbean, and parts of South America, for children living in communities where $\mathrm{HBV}$ is endemic, and children born to immigrant parents from endemic areas. As approximately 5 percent of infants born to HBsAg-positive mothers develop CHB even after optimal immunoprophylaxis, anti-HBs and HBsAg should be tested at 9 to 12 months of age, or one to two months after the last dose of hepatitis B vaccine given to an at risk infant. $(19,20)$

Hepatitis delta (D) infection can occur with CHB and an enzyme immunoassay for anti$\mathrm{HDV}$ is commercially available. Negative anti-HBc IgM, positive $\mathrm{HBsAg}$, and presence of anti-HDV suggest the diagnosis of HDV super-infection. Anti-HDV may take several weeks to develop. Acute and convalescent sera may be required. IgM anti-HDV is not useful since it can persist several months during chronic infection.

\section{Prevention and Treatment}

The combination vaccination strategy (HBIG and HBV vaccine series) for high-risk neonates significantly prevents vertical transmission to neonates born to $\mathrm{HBV}$-infected mothers. Children and adolescents with CHB should be immunized against hepatitis A, if not already immune.

Not all children with CHB would benefit antiviral therapy due to potential side effects and the development of antiviral resistance. Treatment should be considered for children with immune active $\mathrm{CHB}$ regardless of $\mathrm{HBe} \mathrm{Ag}$ status, or if liver biopsy shows moderate to 
severe inflammation or the presence of fibrosis. (21) The goal of treatment for CHB is to suppress HBV replication, reduce liver inflammation, reverse hepatic fibrosis, and prevent the development of cirrhosis and HCC. There are currently several FDA-approved oral antivirals for CHB in adults: three nucleoside drugs (lamivudine, entecavir, and telbivudine) and two nucleotides (adefovir dipivoxil, tenofovir disoproxil fumarate).

The first treatments for children with CHB to be FDA-approved are thrice weekly interferon (IFN) alpha and daily lamivudine for 16-24 weeks for children between age 2 and 18 years.

Although lamivudine is well-tolerated in young children drug resistance is common, in approximately $20 \%$ of patients per year, therefore its use is currently rare. There have been promising results with pegylated interferon (PEG IFN) for adults with CHB, and this treatment is currently being studied in children. Adefovir dipivoxil, a nucleotide analog, is approved for children 12 years old and older but probably has a limited role because higher antiviral activity and lower rates of viral resistance compared to newer agents such as pegylated interferon and entecavir. (23) Entecavir and tenofovir are FDA-approved for adults with CHB and tenofovir disoproxil is FDA-approved for children 12 years and older. (24) The pediatric approval for entecavir was based primarily on a phase 3 randomized trial (NCT01079806) in 180 children between 2 and 18 years of age who had not been previously treated with a nucleoside/nucleotide analog.

Side effects from nucleos(t)ide analogues usually are minimal during clinical trials but more have been reported after post-marketing surveillance. These analogues have activity against human mitochondrial DNA (mtDNA) polymerase gamma and can lead to mitochondrial dysfunction. All five approved agents carry a US Food and Drug Administration black box warning of potential mitochondrial toxicity. Myopathy and neuropathy are commonly reported with lamivudine; nephrotoxicity is fairly common with adefovir and tenofovir; and pancreatitis may be associated with the use of lamivudine or adefovir. Antiviral therapy with nucleos(t)ide analogues for children in the immune-tolerant phase has not been associated with benefits but poses a theoretical risk for the development of antiviral drug resistance or adverse side effects. (25)

The best strategy to control HBV infection in children and adolescents is to implement a universal vaccination program. For newborn infants born to mother with $\mathrm{CHB}$, the current recommendation is the administration of prophylaxis (HBIG and completion of hepatitis B vaccine series with the first dose of hepatitis B vaccine given within 12 hours of birth. (26) The efficacy of the combination of HBIG and HBV vaccine series is not yet $100 \%$ but somewhat higher $(85-95 \%)$ than that of HBV vaccine alone $(65-95 \%)$. The risk of maternal-fetal transmission exists despite double vaccination of infants born to mothers with positive HBeAg and/or a high HBV DNA level. (27) The American Association for the Study of Liver Diseases (AASLD) suggests antiviral therapy to reduce the risk of perinatal transmission of hepatitis B in HBsAg-positive pregnant women with a high viral load. Increasing evidence of the safety of exposing infants to antiviral therapy during pregnancy is available but long-term follow-up is required. (28) However the exact viral load threshold and the timing of when to start therapy during the third trimester have not been clearly 
addressed. Mothers with CHB who have cracked nipples should avoid breastfeeding and should not donate their breast milk.

After a routine series of HBV vaccination, a circulating anti-HBs level of greater than 10 $\mathrm{mIU} / \mathrm{mL}$ is considered to be seroprotective. In immune-competent children, seroprotective levels are achieved in at least $95 \%$ after one course of HBV vaccine. Peak vaccine-induced anti-HBs level is directly related to the waning of the antibody over time which could increase the risk of HBV infection and of chronic HBV carriage. (29)

Following an additional dose of a new HBV vaccine series (the fourth dose), $15-20 \%$ of subjects who fail to respond to the first complete HBV vaccine series will develop a protective antibody response, and $50-75 \%$ will develop such a response after 3 additional doses. Therefore another complete 3-dose series of the HBV vaccine is recommended for non-responders to routine HBV vaccination. Non-responders after 3 additional doses are less likely to have any benefit after the sixth dose and should be tested for HBsAg to determine the possibility of CHB. Immunosupression and certain genetic factors (both HLA and nonHLA genes) may explain such nonresponsiveness to routine and additional HBV vaccination. (29)

\section{Special Considerations}

The influence of age, mode of acquisition, ethnicity and/or HBV genotype on the natural history of CHB in children is variable. Genotype testing is not routinely recommended in clinical practice. HBV genotyping may be considered for $\mathrm{HBeAg}$-positive children who are considering IFN therapy. A response to IFN was more likely observed in genotype A and B than genotype C. HBV genotype may influence HCC development in children differently than in young adults.

The risk for HCC in children increases with age due to the duration of disease, the degree of histologic injury, and the replicative state of the virus (HBV DNA levels). HCC can occur even after viral replication ceases or early $\mathrm{HBeAg}$ seroconversion. (30) It is unclear how to monitor disease progression and the development of HCC in children. The monitoring protocol for HCC for adults with $\mathrm{HBV}$ that is recommended is the combined use of liver ultrasound and serum alpha fetoprotein (AFP) every 12 months or more closely in those with elevated AFP, cirrhosis, or a family history of HCC. (31)

The financial burden for children with CHB is undoubtedly high due to long term exposure of the virus and risks of cirrhosis and HCC. To reduce the financial burden an effective combination therapy of antiviral drugs is required to target the viral replication cycle rather than merely achieving prolonged suppression of viral replication.

Efforts have also focused on searching for natural products as alternative medicines with low cost and safety for the antiviral therapy. In recent decades, a large number of clinical trials and pre-clinical studies using Chinese medicine have demonstrated potential benefit in several aspects of treatment of CHB. Many concerns include study design the quality of clinical trials and the inconsistent and unknown active ingredient components of Chinese medicines in the regimen. (32). 


\section{HCV}

\section{Epidemiology and Natural History}

$\mathrm{HCV}$ infection is a global health burden affecting 170 million individuals worldwide. In the United States, there are approximately 7 million HCV infected adults and 100,000 children (33). In the 3rd National Health and Nutrition Evaluation Survey, the HCV seroprevalence among children was estimated at $0.2 \%$ to $0.4 \%$ ( 132,000 antibody positive children) (34) US census results have estimated that 23,048 to 42,296 children are chronically infected with HCV and 7200 new cases occur annually. (35) Genotype $11 \mathrm{a}$ and $1 \mathrm{~b}$ are the most common subtypes in the U.S., followed by genotypes 2 and 3 and less commonly subtypes 4-6. (36)

Prior to 1992, HCV-infected children acquired the virus through transfusion of blood and blood-related products. Since 1992, blood units transfused have mostly been free of HCV which is estimated to be $0.01 \%-0.001 \%$ per transfusion. (37) Therefore most new HCVinfected cases have occurred through vertical transmission. (35) Maternal-fetal (vertical transmission) accounts for $>60 \%$ of children with $\mathrm{HCV}$ and approximately $5 \%$ of infants are born to HCV-RNA positive woman. (38) Mothers with high viral load (HCV RNA $>10^{6}$ copies $/ \mathrm{ml}$ ) are more likely to transmit the virus to the fetus. HIV co-infected mothers have a 4-5 fold increased risk of vertical transmission. Infants born to HCV-positive mothers are more likely to be of low birth weight, small for gestational age, and require neonatal intensive care unit admission and assisted ventilation compared with uninfected infants. (39)

Mok et al reported that one-third to one-half of infants with HCV had acquired HCV in utero from HCV-infected mothers. (40) HCV was detected in breast milk and colostrum. $(41,42)$ The HCV transmission rate was higher in infants exposed to HCV RNA positive breast milk. (43) Most studies however did not demonstrate an association between transmission and mode of infant feeding $(44,45)$. In contrast to HBV infection in children, children with HCV infection have a higher rate of spontaneous viral clearance. About 25$40 \%$ of infants who acquired HCV via vertical transmission have spontaneous clearance of HCV-RNA by 2-3 years whereas 6-12\% of children up to 7 years exhibit the spontaneous HCV clearance. (46-48) Spontaneous viral clearance more likely occurs with HCV genotype 3 infection.(49) Chen et al reported a study of 42 children chronically infected with $\mathrm{HCV}$, with an RNA level below $4.5 \times 10(4) \mathrm{IU} / \mathrm{mL}$ at enrollment, having a higher rate of spontaneous viral clearance. (50)

On the other hand, children who acquire HCV via the parenteral transmission have highly variable viral clearance. In up to 3 decades of longitudinal cohorts, viral clearance ranged from $11 \%$ and $30-45 \%$ in a study of infants infected by an HCV-RNA-positive blood donor or contaminated blood products during surgery respectively. (51-53) Children with elevated serum aminotransferases at onset of the illness have a greater chance of biochemical remission and loss of viremia compared to those with normal serum aminotransferases (47, 54)

Similar to HBV infection in children, most children ( $80 \%)$ with chronic HCV infection without spontaneous viral clearance have an asymptomatic clinical course with normal 
histology or mildly elevated serum aminotransferases and minimal changes in liver histopathology. $(38,55)$ Up to $10-20 \%$ of HCV-infected children without viral clearance will have persistent elevation of serum aminotransferases and may have clinical manifestations of liver disease. An increase in the aspartate aminotransferase (AST) /alanine aminotransferase (ALT) ratio (AST>ALT) may suggest the development of cirrhosis in individuals with chronic hepatitis $\mathrm{C}(\mathrm{CHC})$. Cirrhosis is reported in 1-2\% of children, and progression to severe chronic liver disease and $\mathrm{HCC}$ occurs $20-40$ years after infection. (56) Two HCV-infected adolescents developed HCC. (57) The first case was a 14-year-old African American girl with vertical transmission of HCV genotype 1a with end stage liver disease requiring liver transplant. Alpha feto protein (AFP) concentration increased from 39.8 to $76.6 \mathrm{ng} / \mathrm{mL}$ (normal $<8.9 \mathrm{ng} / \mathrm{mL}$ ) within 5 months. The pathology of her liver explant showed a single $1.5-\mathrm{cm}$ nodule of well-differentiated HCC. The second case was a 13-year-old Caucasian girl with a T cell-depleted allogeneic stem cell transplant for recurrent acute myelogenous leukemia and elevated serum aminotransferases. HCV PCR was positive and AFP concentration was elevated $(2,740 \mathrm{ng} / \mathrm{mL}$ - normal $<10)$. Computerized axial tomography (CT) scan of the abdomen revealed 2 low-attenuation lesions in the right lobe of the liver. She underwent a right hepatectomy. Multinodular HCC with the margins of the sample free of tumor was noted in the excised liver. Six months after the HCV diagnosis, several low-attenuation lesions were noted in the left lobe of the liver, she had worsening of cholestasis and died after palliative biliary stent placement. The risk of HCC is significantly decreased among HCV-infected adult cases with a sustained viral response (SVR) compared to those without an SVR. $(58,59)$

\section{Diagnosis and Tests}

In general the algorithm for testing and diagnosis of $\mathrm{HCV}$ infection begins with an antibody test in accordance with guidelines/recommendations provided by the American Association for the Study of Liver Diseases in 2009 (60) and the United States Centers for Disease Control and Prevention in 2013. (61) Screening tests for HCV are recommended in children and adolescents with clinical settings of hepatitis or unexplained elevation of serum aminotransferases, with HIV infection, with a history of illicit injection drug use, sexual assault, multiple sexual partners, mothers who are known or suspected to be infected with $\mathrm{HCV}$ or have a history of intravenous drug use, children who are international adoptees or refugees from countries with high prevalence rates including Africa, China, Russia, Eastern Europe, and Southeast Asia. (62) In the setting of either a reactive or indeterminate HCV antibody result, HCV RNA testing should be performed. The diagnosis of HCV infection is confirmed when HCV RNA is detected. (60) However in young infants born to a HCV positive mother, passive (transplacental) maternal antibodies can persist for up to 18 months. Therefore the American Academy of Pediatrics recommends that infants born to HCVinfected mothers be screened by anti-HCV antibody at age 18 months postpartum. (63) In children in whom HCV RNA is not detected, a reactive antibody could indicate either a past $\mathrm{HCV}$ infection with a viral clearance or the antibody test is false-positive. False negative antibody testing could occur in immunocompromised patients especially those with advanced HIV infection, hemodialysis, transplant recipients, or suspected cases with acute HCV infection. Since HCV RNA can be detected within 10-14 days after infection, those 
who with suspicion for acute $\mathrm{HCV}$ infection should have HCV RNA testing performed concomitantly with the antibody testing.

As the initial assay for antibody testing for $\mathrm{HCV}$, several different antibody tests are available, including laboratory based immunoassays, rapid point-of-care tests, and homebased tests, and all can be used. The most common standard test to detect anti-HCV antibodies in serum and plasma is an immunoassay or enzyme-linked immunosorbent assay or EIA. The latest, third generation EIAs (EIA-3) generally detects antibodies to recombinant antigens from the core, NS3, NS4, and NS5 proteins of HCV. (64) These very high sensitivity and high specificity EIA tests become positive as early as eight weeks after exposure. (65) Most rapid tests for HCV antibodies have been developed for HCV testing outside of traditional clinical settings. (66)

Quantitative HCV RNA assays are used to confirm the presence or absence of infection and to quantify the amount of HCV RNA present, to determine SVR and to guide decisions for a duration of antiviral therapy. False positive HCV RNA results can occur in the presence of carryover contamination. Fortunately real-time PCR methods have largely eliminated this issue and replaced standard PCR methods in clinical laboratories for HCV level testing with greater sensitivity with lower detection limits of approximately 15 international units $/ \mathrm{mL}$.

\section{Prevention and Treatment}

Children and adolescents should be immunized against hepatitis A and hepatitis B, if not already immune. Prevention of new HCV infections in older children and adolescents focuses mostly on counseling for high-risk behaviors such as sex with multiple partners, the use of intravenous drugs and/or intranasal cocaine because of sharing of potentially contaminated equipment. Although commercial body piercing and tattooing are not definitely associated with the risk acquiring HCV, self-tattooing and self-piercing with shared needles should be discouraged. (68).

The goal of treatment in HCV infection is achievement of a SVR. Currently SVR is defined as undetectable HCV RNA in peripheral blood 24 weeks after the end of the treatment. Late relapse is rare after SVR. The durability of undetectable serum HCV was observed in almost all cases (>99\%) after SVR. (69). Treatment for HCV-infected children has been guided by clinical trials in adults. Several clinical trials in children were performed to address the efficacy and safety of these therapies. Historically in small uncontrolled clinical trials of thrice-weekly interferon, reported SVR rates are better in children (30\%-60\%) than in adults $(8 \%-35 \%)$. (70) In a small pilot study of long-acting interferon or weekly pegylated interferon alfa-2a (PEG IFN alpha-2a), HCV-infected children 2 to 8 years of age had an SVR of $43 \%$ (46\% in genotype 1). (71) In an open-label uncontrolled pilot study of the combination of PEG IFN alfa-2b plus oral ribavirin (RV) in HCV genotype 1-infected children 2 to 17 years of age achieved an SVR of 48\%. This therapy was, approved for use in children in the US, based on this single uncontrolled trials. (72) For chronic HCV infection (CHC), the current FDA-approved standard of care for children aged 3 to 18 years is once weekly PEG IFN alpha-2a or -2b plus daily ribavirin for 24 weeks in HCV genotype 2 and 3 and for 48 weeks for HCV genotype 1 and 4. (73) 
The Pediatric Study of Hepatitis C (PEDS-C) was a prospective, randomized, controlled trial which demonstrated that early and sustained response rates are significantly increased when $\mathrm{RV}$ is added to PEG IFN alfa-2a vs PEG IFN alfa-2a plus placebo regardless of age, serum aminotransferases levels, and degree of histologic severity. The study indicates that children with chronic hepatitis $\mathrm{C}$ should not receive PEG monotherapy except those with HCV RNA levels less than 600,000 IU/mL who responded well. (55) A systematic review and metaanalysis included eight trials in which 438 children aged 3-18 years were treated with PEG IFN alpha-2a or $-2 b$ and ribavirin. (74) In children with HCV genotype 2 or 3 infection a SVR of $89 \%$ was reported, whereas in children with HCV genotypes 1 or 4 infection the SVR at best occurred in up to 52\%. Combined therapies with Peg-IFN and RV results in a SVR up to $100 \%$ in HCV genotypes 2 or 3 children but only $45-55 \%$ in those infected with genotypes 1 or 4 .

Adverse effects range from more common symptoms including flu-like illness, myalgia, neutropenia, to less commonly observed anemia and thrombocytopenia, thyroid-related symptoms, alopecia, neuropsychiatric manifestations from mood alterations, irritability, agitation and aggressive behavior to depression, anxiety and suicidal ideation). $(38,55)$ Spastic diplegia was sporadically reported in young infants using IFNa . (75) Jonas et al. previously reported that children had significant changes in body weight, linear growth, body mass index and body composition during the treatment with Peg-IFN, which were reversible, although many had height $\mathrm{Z}$ scores that did not return to baseline by 2 years post cessation of treatment. (76) Recently long-term effects on growth were reported in children in children treated with Peg-IFN and RV for 48 weeks and then followed for five years; almost all returned to baseline rates of linear growth velocity. (77) Children who received PEG IFN alfa-2a and RV could rarely develop ophthalmologic complications such as potential severity of ischemic retinopathy and uveitis; thus an ophthalmologic examination is recommended during and after therapy (78). RV may have effects on viral replication, errorprone mutagenesis, decreased intracellular inosine $5^{\prime}$ monophosphate dehydrogenase, and enhanced immune response. $(79,80)$ The administration of $\mathrm{RV}$ requires extreme caution in childbearing-aged adolescents with CHC, given its teratogenic effects. (81)

Direct-acting antiviral agents (DAAs) have fundamentally changed the treatment of $\mathrm{HCV}$ infection. DAAs are uniquely designed to inhibit three viral proteins: NS3/4A protease, NS5B RNA-dependent polymerase, and NS5AProtein, so-called HCV protease inhibitors (PIs), nucleoside HCV polymerase inhibitors (NIs), and nonnucleoside HCV polymerase inhibitors (NNIs) respectively. When PIs (telaprevir and boceprevir) were added to baseline regimens of PEG alfa-2a and RV, SVR improved up to $75 \%$ in genotype 1 treatment-naïve patients. (82) Both PIs entered pediatric trials in 2008 (83). Due to side effects of telaprevir including severe rash and the black-box warning of Steven-Johnson syndrome and dysgeusia in boceprevir, both drugs were removed from the market.

Some children who are previous non-responders with IFN alpha therapy plus RV could potentially be retreated with PEG IFN and RV. However since the treatment using PEG IFN alpha $2 \mathrm{a}$ and $\mathrm{RV}$ is associated with several adverse effects, the efficacy and applicability can be limited in patients with CHC-induced liver disease. (84) In addition the treatment is relatively contraindicated in end-stage liver and renal disease. The improvement of existing 
therapies and development of new effective, safe, and tolerable drugs is therefore necessary. When risk-benefit ratio is considered, children with genotype 2 and 3 , younger children with CHC genotype 1, children with normal serum aminotransferases probably have milder hepatic disease, higher possibility of spontaneous viral clearance, and lower risk of cirrhosis and HCC development and could wait for more efficient antiviral therapy with fewer side effects. Excellent results from recent and ongoing trials with DAA's other than telaprevir and boceprevir in adults show shorter duration and high tolerance. The combination of newer NS3/4A PI (simeprevir) and NS5B RNA-dependent PI (sofosbuvir) can further improve response rates, reduce the length of antiviral treatment with or without IFN alpha or $\mathrm{RV}$ regimen in both treatment-naive and previous non-responders with genotype 1 chronic HCV. $(85,86)$ Adverse effects of the regimen such as fatigue, headache and nausea were reported to be mild. (87) Last but not least, $95-100 \%$ of patients with genotype 1 infection achieved a SVR at 12 weeks in a recent trial using fixed dose combination of sofosbuvir and the NS5A inhibitor ledipasvir alone or with RV administered for 8-12 weeks in both adults with a treatment history or the presence of compensated cirrhosis. (88) As of September 2016, 10 DAAs were approved for adults and combined into 6 regimens given for different durations depending upon HCV genotypes targeted. These therapeutic advances are currently leading to clinical trials to the pediatric population. Until DAA,s are approved in children with HCV, an expectant approach is advocated and treatments which are FDAapproved for adults but not yet children should be considered only to those at high risk for more severe, progressive liver diseases.

\section{Special considerations and Controversies}

Compared to adults with $\mathrm{CHC}$, children have different modes of transmission, spontaneous and treatment rates of clearance, slow progression of fibrosis. (89) The accumulative duration of $\mathrm{HCV}$ infection since birth theoretically makes children with vertical transmission of $\mathrm{HCV}$ at risk for cirrhosis and HCC by the time of the transition to the adulthood. Figure 1 provides recommendations to pediatricians and pediatric gastroenterologists to monitoring and/or managing children with $\mathrm{CHC}$. As the field of hepatitis $\mathrm{C}$ therapy is rapidly progressing, DAAs have proven to be efficient therapy even in HCV-infected adults with compensated cirrhosis. Pretreatment liver histology does not necessarily predict the response. A new IFN-free, DAA-based combination: sofosbuvir $(400 \mathrm{mg}$ ) plus ledipasvir $(90 \mathrm{mg})$ in one single tablet - was approved in 2014 in the United States for adults; clinical trials are ongoing to improve tolerability and compliance in children. (90)

A subgroup of high risk children with end-stage or decompensated liver diseases may benefit from DAA's trials prior to a consideration for liver transplantation as the outcome of liver transplantation in adults with $\mathrm{CHC}$ has been suboptimal with development of recurrent HCV infection in most recipients prior to the advent of DAA therapy. (91) Other factors to consider which may affect HCV and the treatment include obesity and vitamin D status. (92-94) Several pediatric studies indicate most children had mild or minimal hepatic fibrosis. (95) Therefore the role of obtaining a liver biopsy prior to treatment of children with $\mathrm{CHC}$ is unclear. If liver fibrosis plays a pivotal role in the timing of an antiviral therapy or selecting appropriate therapies, non-invasive markers may guide treatment in children with CHC. (96) With the development of newer therapies in children, some factors such as 
IL-28B receptor polymorphism or pretreatment HCV RNA levels may predict a higher SVR with shorter duration of therapy $(55,76,97)$ Currently there is no definite consensus regarding longitudinal monitoring and timing of treatment of asymptomatic children with HCV infection. HCV-infected children with significant liver disease should have annual or biannual abdominal sonography and serum AFP. (73) This raise concerns to parents caring children with CHC. Although global impairment in QOL, cognitive, behavioral, or emotional functioning is not a concern in young children with HCV infection, Rodrigue et al reported that stress and strain on the family system in caregiver stress may be associated with some cognitive changes in children given a parental guilt since the majority of cases were vertical transmission. (98) After weighing the risk/benefit decisions towards treatment, there is always a fear of induction of drug resistance. Resistance-associated variants with reduced sensitivity to DAA's have been reported. (99) Considering treating children with $\mathrm{CHC}$, the financial burden of $\mathrm{HCV}$ is high. Jhaveri et al estimated the direct medical costs for the care of children with CHC: US\$26 million for screening, \$117-206 million for monitoring, and \$56-104 million for treatment costs. (35) As CHC is becoming a serious health issue in children transitioning to the adulthood, increased efforts and resources to identify more effective prevention will certainly be cost-effective.

\section{References}

1. Palumbo E. Hepatitis B genotypes and response to antiviral therapy: a review. Am J Ther. 2007; 14:306-9. [PubMed: 17515708]

2. Chan HL, Hui AY, Wong ML, Tse AM, Hung LC, Wong VW, Sung JJ. Genotype C hepatitis B virus infection is associated with an increased risk of hepatocellular carcinoma. Gut. 2004; 53:1494-8. [PubMed: 15361502]

3. Euler GL, Wooten KG, Baughman AL, Williams WW. Hepatitis B surface antigen prevalence among pregnant women in urban areas: implications for testing, reporting, and preventing perinatal transmission. Pediatrics. 2003; 111:1192-7. [PubMed: 12728137]

4. Xu DZ, Yan YP, Choi BC, et al. Risk factors and mechanism of transplacental transmission of hepatitis B virus: a case-control study. J Med Virol. 2002; 67:20-618. [PubMed: 11920813]

5. Willner IR, Uhl MD, Howard SC, et al. Serious hepatitis A: an analysis of patients hospitalized during an urban epidemic in the United States. Ann Intern Med. 1998; 128:111-14. [PubMed: 9441570]

6. Lin HH, Lee TY, Chen DS, et al. Transplacental leakage of HBeAg-positive maternal blood as the most likely route in causing intrauterine infection with hepatitis B virus. J Pediatr. 1987; 111:877. [PubMed: 3681555]

7. Ohto H, Lin HH, Kawana T, Etoh T, Tohyama H. Intrauterine transmission of hepatitis B virus is closely related to placental leakage. J Med Virol. 1987; 21:1. [PubMed: 2947972]

8. Alexander JM, Ramus R, Jackson G, et al. Risk of hepatitis B transmission after amniocentesis in chronic hepatitis B carriers. Infect Dis Obstet Gynecol. 1999; 7:283-6. [PubMed: 10598917]

9. Beasley RP, Stevens CE, Shiao IS, Meng HC. Evidence against breast-feeding as a mechanism for vertical transmission of hepatitis B. Lancet. 1975; 2:740. [PubMed: 52772]

10. Hill JB, Sheffield JS, Kim MJ, Alexander JM, Sercely B, Wendel GD. Risk of hepatitis B transmission in breast-fed infants of chronic hepatitis B carriers. Obstet Gynecol. 2002; 99:1049. [PubMed: 12052598]

11. Wang J, Zhu Q, Zhang X. Effect of delivery mode on maternal-infant transmission of hepatitis B virus by immunoprophylaxis. Chin Med J. 2002; 115:1510-2. [PubMed: 12490098]

12. Shepard, TH. Catalog of teratogenic agents pp 1309. 9. Baltimore, MD: Johns Hopkins University Press; 1998. p. 1309 
13. Livingston SE, Simonetti JP, Bulkow LR, et al. Clearance of hepatitis B e antigen in patients with chronic hepatitis B and genotypes A, B, C, D, and F. Gastroenterology. 2007; 133:1452-7. [PubMed: 17920063]

14. Goldstein ST, Alter MJ, Williams IT, et al. Incidence and risk factors for acute hepatitis B in the United States, 1982-1998: implications for vaccination programs. J Infect Dis. 2002; 185:713-9. [PubMed: 11920288]

15. Bortolotti F, Cadrobbi P, Crivellaro C, et al. Long-term outcome of chronic type B hepatitis in patients who acquire hepatitis B virus infection in childhood. Gastroenterology. 1990; 99:805-10. [PubMed: 2379783]

16. Bortolotti F, Jara P, Crivellaro C, et al. Outcome of chronic hepatitis B in Caucasian children during a 20-year observation period. J Hepatol. 1998; 29:184-90. [PubMed: 9722198]

17. Hsu YS, Chien RN, Yeh CT, Sheen IS, Chiou HY, Chu CM, Liaw YF. Long-term outcome after spontaneous HBeAg seroconversion in patients with chronic hepatitis B. Hepatology. 2002; 35:1522. [PubMed: 12029639]

18. Haber BA, Block JM, Jonas MM, et al. Hepatitis B Foundation. Recommendations for screening, monitoring, and referral of pediatric chronic hepatitis B. Pediatrics. 2009; 124:e1007. [PubMed: 19805457]

19. Workowski KA, Bolan GA. Centers for Disease Control and Prevention. Sexually transmitted diseases treatment guidelines, 2015. MMWR Recomm Rep. 2015; 64(RR-03):1.

20. American Academy of Pediatrics. Medical evaluation of internationally adopted children for infectious diseases. In: Pickering, LK.Baker, CJ.Kimberlin, DW., Long, SS., editors. Red Book: 2012 Report of the Committee on Infectious Diseases. 29. American Academy of Pediatrics; Elk Grove Village, IL: 2012. p. 193

21. Jonas MM, Block JM, Haber BA, et al. Treatment of children with chronic hepatitis B virus infection in the United States: patient selection and therapeutic options. Hepatology. 2010; 52:2192-205. [PubMed: 20890947]

22. Sokal EM, Clonjeevaram HS, Roberts EA, et al. Interferon alfa therapy for chronic hepatitis B in children: a multinational randomized controlled trial. Gastroenterology. 1998; 114:988-95. [PubMed: 9558288]

23. Jonas MM, Kelly D, pollack H, et al. Safety, efficacy, and pharmacokinetics of adefovir dipivoxil in children and adolescents (age 2 to < 18 years) with chronic hepatitis B. Hepatology. 2008; 47:1863-71. [PubMed: 18433023]

24. Murray KF, Szenborn L, Wysocki J, et al. Randomized, placebo-controlled trial of tenofovir disoproxil fumarate in adolescents with chronic hepatitis B. Hepatology. 2012; 56:2018-26. [PubMed: 22544804]

25. Khungar V, Han S. A Systematic Review of Side Effects of Nucleoside and Nucleotide Drugs Used for Treatment of Chronic Hepatitis B. Curr Hepatitis Rep. 2010; 9:75-90.

26. Recommendations of the Immunization Practices Advisory Committee (ACIP). Hepatitis B virus: a comprehensive strategy for eliminating transmission in the United States through universal childhood vaccination. MMWR Recomm Rep. 1991; 40(RR-13):1-25.

27. Wong VC, Ip HM, Reesink HW, et al. Prevention of the HBsAg carrier state in newborn infants of mothers who are chronic carriers of HBsAg and HBeAg by administration of hepatitis-B vaccine and hepatitis-B immunoglobulin. Double-blind randomised placebo-controlled study. Lancet. 1984; 1:1-6. [PubMed: 6140340]

28. Zeng H, Cai H, Wang Y, Shen Y. Growth and development of children prenatally exposed to telbivudine administered for the treatment of chronic hepatitis B in their mothers. Int J Infect Dis. 2015; 33:97-10. [PubMed: 25449229]

29. Hennig BJ, Fielding K, Broxholme J, et al. Host genetic factors and vaccine-induced immunity to hepatitis B virus infection. PLoS One. 2008; 26:3, e1898.

30. Wen WH, Chang MH, Hsu HY, Ni YH, Chen HL. The development of hepatocellular carcinoma among prospectively followed children with chronic hepatitis B virus infection. J Pediatr. 2004; 144(3):397. [PubMed: 15001956] 
31. European Association for Study of Liver, European Organisation for Research and Treatment of Cancer. EASL-EORTC clinical practice guidelines: management of hepatocellular carcinoma. Eur J Cancer. 2012; 48:599-641. [PubMed: 22424278]

32. Wang G, Zhang L, Bonkovsky HL. Chinese medicine for treatment of chronic hepatitis B. Chin J Integr Med. 2012; 18:253-5. [PubMed: 22457135] Zhang L, Wang G, Hou W, Li P, Dulin A, Bonkovsky HL. Contemporary clinical research of traditional Chinese medicines for chronic hepatitis B in China: an analytical review. Hepatology. 2010 Feb; 51(2):690-8. [PubMed: 20101751]

33. Jonas M. Children with hepatitis C. Hepatology. 2003; 36:S173-8.

34. Alter MJ, Kruszon-Moran D, Nainan OV, et al. The prevalence of hepatitis C virus infection in the United States, 1988 through 1994. N Engl J Med. 1999; 341:556-562. [PubMed: 10451460]

35. Jhaveri R, Grant W, Kauf TL, et al. The burden of hepatitis C virus infection in children; estimated direct medical costs over a ten year period. J Pediatr. 2006; 148:353-358. [PubMed: 16615966]

36. Nainan OV, Alter MJ, Kruszon-Moran D, Gao FX, Xia G, McQuillan G, et al. Hepatitis C virus genotypes and viral concentrations in participants of a general population survey in the United States. Gastroenterology. 2006; 131:478-484. [PubMed: 16890602]

37. Luban NL, Colvin CA, Mohan P, Alter HJ. The epidemiology of transfusion-associated hepatitis C in a children's hospital. Transfusion. 2007; 47:615-620. [PubMed: 17381619]

38. Granot E, Sokal EM. Hepatitis C Virus in Children: Deferring Treatment in Expectation of DirectActing Antiviral Agents. Isr Med Assoc J. 2015; 17:707-11. [PubMed: 26757569]

39. Pergam SA, Wang CC, Gardella CM, et al. Pregnancy complications associated with hepatitis C: data from a 2003-2005 Washington state birth cohort. Am J Obstet Gynecol. 2008; 199:38e1-9. [PubMed: 18486089]

40. Mok J, Pembrey L, Tovo PA, Newell ML. European Paediatric Hepatitis C Virus Network. When does mother to child transmission of hepatitis C virus occur? Arch Dis Child Fetal Neonatal Ed. 2005; 90:F156-60. [PubMed: 15724041]

41. Lin HH, Kao JH, Hsu HY, et al. Absence of infection in breast-fed infants born to hepatitis C virusinfected mothers. J Pediatr. 1995; 126:589-91. [PubMed: 7535353]

42. Kumar RM, Shahul S. Role of breastfeeding in transmission of hepatitis C virus to infants of HCVinfected mothers. J Hepatol. 1998; 29:191-7. [PubMed: 9722199]

43. Ruiz-Extremera A, Salmeron J, Torres C, et al. Follow-up of transmission of hepatitis C to babies of human immunodeficiency virus negative women: the role of breastfeeding in transmission. Pediatr Infect Dis J. 2000; 19:511-16. [PubMed: 10877164]

44. Granovsky MO, Minkoff HL, Tess BH, et al. Hepatitis C virus infection in the mothers and infants cohort study. Pediatrics. 1998; 102:355-9. [PubMed: 9685438]

45. Resti M, Azzari C, Mannelli F, et al. Mother-to-child transmission of hepatitis C virus: prospective study of risk factors and timing of infection in children born to women seronegative for HIV-1. BMJ. 1998; 317:437-41. [PubMed: 9703524]

46. Resti M, Bortolotti F, Vajro P, et al. Guidelines for the screening and follow-up of infants born to anti-HCV positive mothers. Dig Liver Dis. 2003; 35:453-7. [PubMed: 12870728] Resti M, Jara P, Hierro L, et al. Clinical features and progression of perinatally acquired hepatitis $\mathrm{C}$ virus infection. J Med Virol. 2003; 70:373-7. [PubMed: 12766999]

47. Resti M, Jara P, Hierro L, et al. Clinical features and progression of perinatally acquired hepatitis C virus infection. J Med Virol. 2003; 70:373-7. [PubMed: 12766999]

48. Yeung LT, To T, King SM, et al. Spontaneous clearance of childhood hepatitis C virus infection. J Viral Hepatol. 2007; 14:797-805.

49. Bortolotti F, Verucchi G, Camma C, et al. Long-term course of chronic hepatitis C in children: from viral clearance to end-stage liver disease. Gastroenterology. 2008; 134:1900-7. [PubMed: 18439604]

50. Chen ST, Ni YH, Chen PJ, et al. Low viraemia at enrollment in children with chronic hepatitis C favours spontaneous viral clearance. J Viral Hepat. 2009; 16:796-801. [PubMed: 19413696]

51. Casiraghi MA, De PM, Romano L, et al. Long-term outcome (35 years) of hepatitis C after acquisition of infection through mini transfusions of blood given at birth. Hepatology. 2004; 39:90-6. [PubMed: 14752827] 
52. Vogt M, Lang T, Frosner G, et al. Prevalence and clinical outcome of hepatitis C infection in children who underwent cardiac surgery before the implementation of blood-donor screening. $\mathrm{N}$ Engl J Med. 1999; 341:866-70. [PubMed: 10498458]

53. Locasciulli A, Testa M, Pontisso $P$, et al. Prevalence and natural history of hepatitis $\mathrm{C}$ infection in patients cured of childhood leukemia. Blood. 1997; 90:4628-33. [PubMed: 9373275]

54. Farmand S, Wirth S, Loffler H, et al. Spontaneous clearance of hepatitis C virus in vertically infected children. Eur J Pediatr. 2012; 171:253-8. [PubMed: 21735055]

55. Schwarz KB, Gonzalez-Peralta RP, Murray KF, et al. Peds-C Clinical Research Network. The combination of ribavirin and peginterferon is superior to peginterferon and placebo for children and adolescents with chronic hepatitis C. Gastroenterology. 2011; 140:450-458. e1. [PubMed: 21036173]

56. Alter HJ, Seeff LB. Recovery, persistence, and sequelae in hepatitis C virus infection: a perspective on long-term outcome. Semin Liver Dis. 2000; 20:17-35. [PubMed: 10895429]

57. González-Peralta RP, Langham MR Jr, Andres JM, Mohan P, Colombani PM, Alford MK, Schwarz KB. Hepatocellular carcinoma in 2 young adolescents with chronic hepatitis C. J Pediatr Gastroenterol Nutr. 2009; 48:630-5. [PubMed: 19412012]

58. Nishiguchi S, Kuroki T, Nakatani S, et al. Randomised trial of effects of interferon-alpha on incidence of hepatocellular carcinoma in chronic active hepatitis C with cirrhosis. Lancet. 1995; 346:1051-1055. [PubMed: 7564784]

59. Nishiguchi S, Shiomi S, Nakatani S, et al. Prevention of hepatocellular carcinoma in patients with chronic active hepatitis C and cirrhosis. Lancet. 2001; 357:196-197. [PubMed: 11213099]

60. Ghany MG, Strader DB, Thomas DL, et al. Diagnosis, management, and treatment of hepatitis C: an update. Hepatology. 2009; 49:1335. [PubMed: 19330875]

61. Centers for Disease Control and Prevention (CDC). Testing for HCV infection: an update of guidance for clinicians and laboratorians. MMWR Morb Mortal Wkly Rep. 2013; 62:362. [PubMed: 23657112]

62. American Academy of Pediatrics. Medical evaluation of internationally adopted children for infectious diseases. In: Kimberlin, DW.Brady, MT.Jackson, MA., Long, SS., editors. Red Book: 2015 Report of the Committee on Infectious Diseases. 30. American Academy of Pediatrics; Elk Grove Village, IL: 2015. p. 194

63. American Academy of Pediatrics. Committee on Infectious Diseases. Hepatitis C virus infection. Pediatrics. 1998; 101:481-485. [PubMed: 9499195]

64. Gretch DR. Diagnostic tests for hepatitis C. Hepatology. 1997; 26:43S. [PubMed: 9305663]

65. Maheshwari A, Thuluvath PJ. Management of acute hepatitis C. Clin Liver Dis. 2010; 14:169. [PubMed: 20123448]

66. Stockman LJ, Guilfoye SM, Benoit AL, et al. Rapid hepatitis C testing among persons at increased risk for infection--Wisconsin, 2012-2013. MMWR Morb Mortal Wkly Rep. 2014; 63:309. [PubMed: 24717818]

67. Chevaliez S, Bouvier-Alias M, Brillet R, Pawlotsky JM. Overestimation and underestimation of hepatitis $\mathrm{C}$ virus RNA levels in a widely used real-time polymerase chain reaction-based method. Hepatology. 2007; 46:22. [PubMed: 17525931]

68. Murray KF, Richardson LP, Morishima C, Owens JW, Gretch DR. Prevalence of hepatitis C virus infection and risk factors in an incarcerated juvenile population: a pilot study. Pediatrics. 2003; 111:153. [PubMed: 12509569]

69. Nelson DR, Davis GL, Jacobson I, et al. Hepatitis C virus: a critical appraisal of approaches to therapy. Clin Gastroenterol Hepatol. 2009; 7:397-414. [PubMed: 19114127]

70. Jacobson KR, Murray K, Zellos A, et al. An analysis of published trials of interferon in children with chronic hepatitis C. J Pediatr Gastroenterol Nutr. 2002; 34:52-58. [PubMed: 11753165]

71. Schwarz KB, Mohan P, Narkewicz MR, et al. Safety, efficacy and pharmacokinetics of peginterferon_2a (40 kd) in children with chronic hepatitis C. J Pediatr Gastroenterol Nutr. 2006; 43:499-505. [PubMed: 17033526]

72. Wirth S, Pieper-Boustani H, Lang T, et al. Peginterferon alfa-2b plus ribavirin treatment in children and adolescents with chronic hepatitis C. Hepatology. 2005; 41:1013-1018. [PubMed: 15793840] 
73. Mack CL, Gonzalez-Peralta RP, Gupta N, et al. NASPGHAN practice guidelines: Diagnosis and management of hepatitis $\mathrm{C}$ infection in infants, children, and adolscents. J Pediatr Gastroenterol Nutr. 2012; 54:838-55. [PubMed: 22487950]

74. Druyts E, Thorlund K, Wu P, et al. Efficacy and safety of pegylated interferon alfa-2a or alfa-2b plus ribavirin for the treatment of chronic hepatitis $\mathrm{C}$ in children and adolescents: a systematic review and meta-analysis. Clin Infect Dis. 2013; 56:961-7. [PubMed: 23243171]

75. Wörle H, Maass E, Köhler B, Treuner J. Interferon alpha-2a therapy in haemangiomas of infancy: spastic diplegia as a severe complication. Eur J Pediatr. 1999; 158:344. [PubMed: 10206141]

76. Jonas MM, Balistreri W, Gonzalez-Peralta RP, et al. Pegylated interferon for chronic hepatitis C in children affects growth and body composition: results from the pediatric study of hepatitis $\mathrm{C}$ (PEDS-C) trial. Hepatology. 2012; 56:523-31. [PubMed: 22383118]

77. Haber B, Alonso E, Pedreira A, et al. Long-term Follow-up of Children Treated With Peginterferon and Ribavirin for Hepatitis C Virus Infection. J Pediatr Gastroenterol Nutr. 2016 Apr 21.

78. Narkewicz MR, Rosenthal P, Schwarz KB, et al. Ophthalmologic complications in children with chronic hepatitis C treated wtih pegylated interferon. J Pediatr Gastroenterol Nutr. 2010; 51:183-6. [PubMed: 20512062]

79. Te HS, Randall G, Jensen DM. Mechanism of action of ribavirin in the treatment of chronic hepatitis C. Gastroenterol Hepatol. 2007; 3:218-226.

80. Castellvi P, Navinés R, Gutierrez F, et al. Pegylated interferon and ribavirin-induced depression in chronic hepatitis C: role of personality. J Clin Psychiatry. 2009; 70:817-828. [PubMed: 19573480]

81. Karnsakul W, Alford MK, Schwarz KB. Managing pediatric hepatitis C: current and emerging treatment options. Ther Clin Risk Manag. 2009; 5:651-60. [PubMed: 19707281]

82. Jacobson IM, McHutchison JG, Dusheiko G, et al. Telaprevir for previously untreated chronic hepatitis C virus infection. N Engl J Med. 2011; 364:2405-16. [PubMed: 21696307] Poordad F, McCone J Jr, Bacon BR, et al. Boceprevir for untreated chronic HCV genotype 1 infection. N Engl J Med. 2011; 364:1195-206. [PubMed: 21449783]

83. Brown NA. Progress towards improving antiviral therapy for hepatitis $C$ with hepatitis $C$ virus polymerase inhibitors. Part I: Nucleoside analogues. Expert Opin Investig Drugs. 2009; 18:709_ 725.

84. Masci P, Bukowski RM, Patten PA, Osborn BL, Borden EC. New and modified IFN alfas: preclinical and clinical data. Curr Oncol Rep. 2003; 5:108-113. [PubMed: 12583827]

85. Everson G, Cooper C, Hezode C, et al. DAUPHINE: a randomized phase II study of danoprevir/ ritonavir plus peginterferon alpha-2a/ribavirin in HCV genotypes 1 or 4. Liver Int. 2014; 35:10819. [PubMed: 24517252]

86. Fried MW, Buti M, Dore GJ, et al. Once-daily simeprevir (TMC435) with pegylated interferon and ribavirin in treatment-naive genotype 1 hepatitis C: the randomized PILLAR study. Hepatology. 2013; 58:1918-29. [PubMed: 23907700]

87. Lawitz E, Sulkowski MS, Ghalib R, et al. Simeprevir plus sofosbuvir, with or without ribavirin, to treat chronic infection with hepatitis $\mathrm{C}$ virus genotype 1 in non-responders to pegylated interferon and ribavirin and treatment-naïve patients: the COSMOS randomised study. Lancet. 2014; 384:1756-65. [PubMed: 25078309]

88. Gentile I, Buonomo AR, Zappulo E, et al. Interferon-free therapies for chronic hepatitis C: toward a hepatitis C virus-free world? Expert Rev Anti Infect Ther. 2014; 12:763-73. [PubMed: 24918116]

89. Murray KF, Finn LS, Taylor SL, Seidel KD, Larson AM. Liver histology and alanine aminotransferase levels in children and adults with chronic hepatitis $\mathrm{C}$ infection. J Pediatr Gastroenterol Nutr. 2005; 41:634-8. [PubMed: 16254522]

90. Afdhal N, Zeuzem S, Kwo P, et al. Ledipasvir and sofosbuvir for untreated HCV genotype 1 infection. N Engl J Med. 2014; 370:1889-98. [PubMed: 24725239]

91. Berenguer M, Prieto M, Palau A, et al. Severe recurrent hepatitis C after liver retransplantation for hepatitis C virus-related graft cirrhosis. Liver Transpl. 2003; 9:228-235. [PubMed: 12619018]

92. Delgado-Borrego A, Healey D, Negre B, et al. Jonas MM. Influence of body mass index on outcome of pediatric chronic hepatitis C virus infection. J Pediatr Gastroenterol Nutr. 2010; 51:191-7. [PubMed: 20531022] 
93. Eltayeb AA, Abdou MA, Abdel-aal AM, Othman MH. Vitamin D status and viral response to therapy in hepatitis C infected children. World J Gastroenterol. 2015; 21:1284-91. [PubMed: 25632203]

94. Villar LM, Del Campo JA, Ranchal I, Lampe E, Romero-Gomez M. Association between vitamin D and hepatitis C virus infection: a meta-analysis. World J Gastroenterol. 2013; 19:5917-24. [PubMed: 24124339]

95. Goodman ZD, Makhlouf HR, Liu L, et al. Pathology of chronic hepatitis C in children: liver biopsy findings in the Peds-C Trial. Hepatology. 2008; 47:836-43. [PubMed: 18167062]

96. Lee CK, Perez-Atayde AR, Mitchell PD, Raza R, Afdhal NH, Jonas MM. Serum biomarkers and transient elastography as predictors of advanced liver fibrosis in a United States cohort: the Boston children's hospital experience. J Pediatr. 2013; 163:1058-64. [PubMed: 23759423]

97. Domagalski K, Pawlowska M, Tretyn A, et al. Impact of IL-28B polymorphisms on pegylated interferon plus ribavirin treatment response in children and adolescents infected with HCV genotypes 1 and 4. Eur J Clin Microbiol Infect Dis. 2013; 32:745-54. [PubMed: 23314745]

98. Rodrigue JR, Balistreri W, Haber B, et al. Impact of hepatitis C virus infection on children and their caregivers: quality of life, cognitive, and emotional outcomes. J Pediatr Gastroenterol Nutr. 2009; 48:341-7. [PubMed: 19242286]

99. Sarrazin C, Dvory-Sobol H, Svarovskaia ES, et al. Prevalence of Resistance-Associated Substitutions in HCV NS5A, NS5B, or NS3 and Outcomes of Treatment With Ledipasvir and Sofosbuvir. Gastroenterology. 2016; 151:501-512. [PubMed: 27296509] 


\section{Key Points}

List 3 to 5 key points of approximately 25 words each that summarize the main points of the article. Key points appear beneath the article title and authors in print and online

1. The disease burden for both HBV and HCV infection in the pediatric population is high as most infected children acquire the virus via maternal fetal transmission.

2. Without spontaneous viral clearance or indications to treat, the majority of HBV- and HCV-infected children will become adults with chronic viral hepatitis and liver disease.

3. The goal of treatment for $\mathrm{HCV}$ infection is to achieve a sustained virologic response (ie sustained viral clearance). The goal of treatment for HBV infection is to achieve a "functional cure" meaning that circulating markers of viral infection are negative but there may be residual ccc HBV DNA in the liver.

4. Successful antiviral treatment in adults with HBV and HCV infection gives promise to guide therapy in children; however there are differences between adults and children with these infections, including in natural history, pharmacokinetics, responses to therapy, and short and long term adverse effects of antiviral agents.

5. Apart from antiviral therapies, prevention of the diseases is important as transmission largely occurs during the perinatal period. 


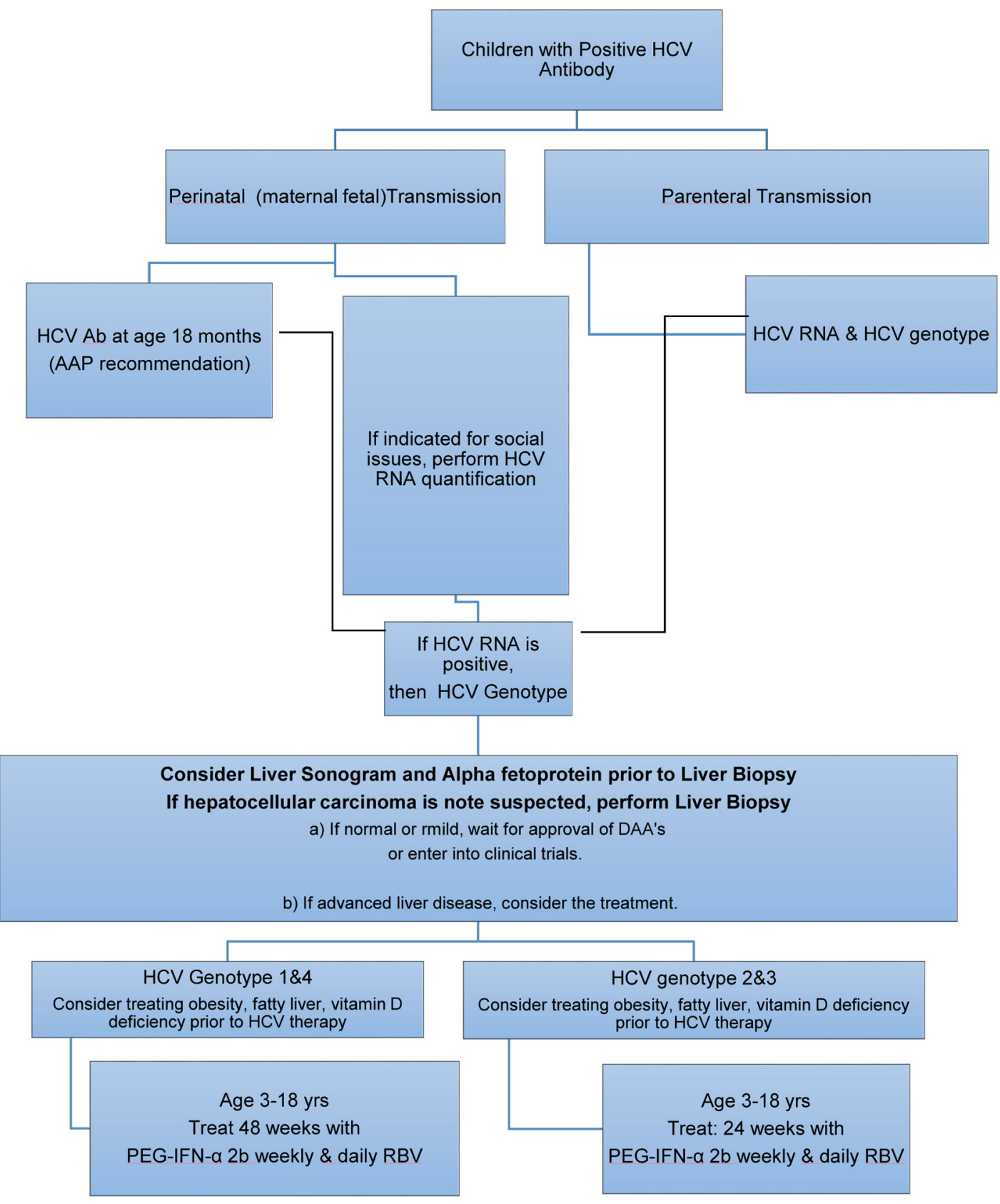

Figure 1.

Recommended Approach to Monitoring and/or Managing Children with Chronic Hepatitis C Infection indicated as having $\mathrm{HCV}$ infection for greater than 6 months 


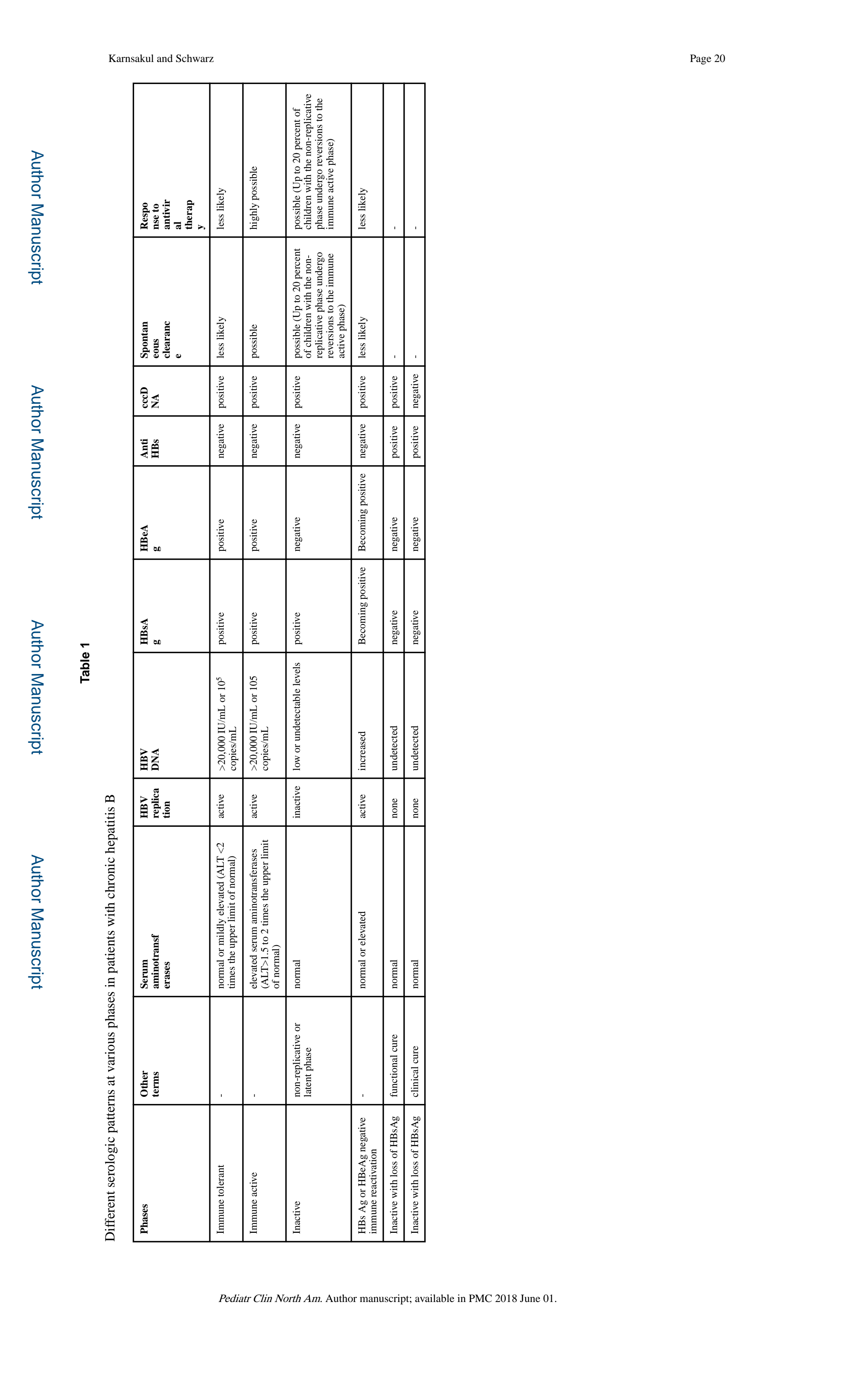

